\title{
Visualization of Different Morphological Structures within Pigmented Melanocytic Skin Lesion Melanoma: Case Studies
}

\section{Irdina Drljevic $^{1^{*}}$ and Kenan Drljevic ${ }^{2}$}

${ }^{1}$ Clinic of Dermatology and Venereology, Clinical Centre of the University of Sarajevo, Bolnička, Sarajevo, Bosnia and Herzegovina, Balkans

2Obstetrics and Gynaecology Department, General Hospital, Kranjčevićeva, Sarajevo, Bosnia and Herzegovina, Balkans

"Corresponding author: Irdina Drljevic, Clinic of Dermatology and Venereology, Clinical Centre of the University of Sarajevo, Bolnička 25, 71000 Sarajevo, Bosnia and Herzegovina, Balkans, Tel: +387 33 297-000; E-mail: idrljevic@hs-hkb.ba

Received date: March 31, 2017; Accepted date: April 17, 2017; Published date: April 24, 2017

Copyright: (C) 2017 Drljevic I, et al. This is an open-access article distributed under the terms of the Creative Commons Attribution License, which permits unrestricted use, distribution, and reproduction in any medium, provided the original author and source are credited.

\begin{abstract}
Dermoscopy is valid, non-invasive technique for the visualization of different morphological structures within pigmented melanocytic skin lesion. In clinical practice, positive personal history is considered to be as an indication of increased melanoma risk. The thickness of melanoma (Breslow Index) is the most important independent predicting factor of survival for stage I patients. We aimed to present two cases of head-melanoma and discuss prominent clinical and dermoscopic features across the spectrum of "hidden-melanoma" and differential diagnosis.
\end{abstract}

Keywords: Skin; Head; Melanoma; Dermoscopy; Differential diagnosis

\section{Introduction}

Melanoma is a malignant tumor of melanocytes, whose incidence has been increasing all over the world. Most authors believe that there is still no specific diagnostic criterion enabling an unambiguous clinical diagnosis of melanoma [1]. Most often it is found on skin, which should direct doctors and patients to early recognition and detection of the disease [2]. Scalp melanoma is included in the group of head and neck melanomas, which make approximately $10-20 \%$ of all primary skin melanomas [3]. It is defined as a tumor usually located in the area of the head covered with hair (hair-bearing area melanoma) and it is also called "hidden" melanoma or "invisible killer" [4]. Lentigo malign melanoma is the most frequent histological subtype of melanoma in elderly women, whereas superficially spreading and nodular melanomas are found in the scalp area in men, mostly older than 50 [5].

\section{Case Study I}

A 45 year old patient presented to a dermatologist for occasional bleeding of a mole in the right retroauricular region (as shown in Figure 1). He had noticed first changes of color and size of the mole a year before. His mother's brother had had a similar tumor operated a few years ago. Before the age of 20 he had had several sunburns.

At the moment of the examination a slightly elevated macula measuring $16 \times 14 \mathrm{~mm}$ could be seen, it was dark brown and black, with irregular contours and wet. Dermatoscopic examination was done with the digital dermatoscope MoleMax II and under twenty times magnification the following dermatoscopic structures were noticed: atypical pigment network, irregular streaks, homogeneous area, irregular dots and globules, blue-white veil (Figure 2). An operative treatment and extirpation of the first sentinel lymph node were recommended. Histological testing by standard hematoxylin-eosin (HE) technique showed that it was a superficial spreading melanoma with a phase of vertical growth and multifocally present ulcerations of epidermis.

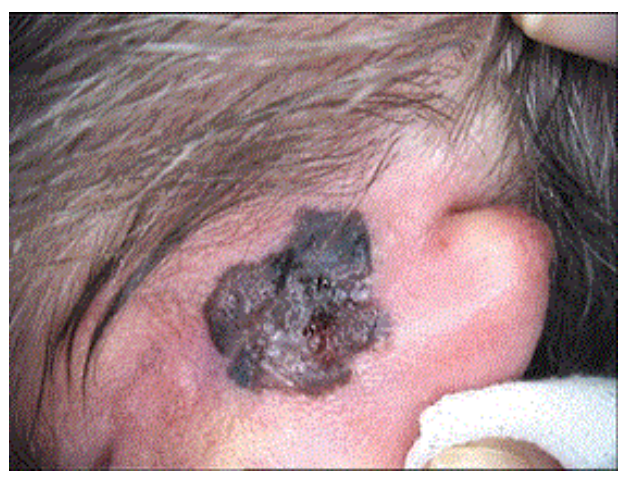

Figure 1: Superficial spreading melanoma.

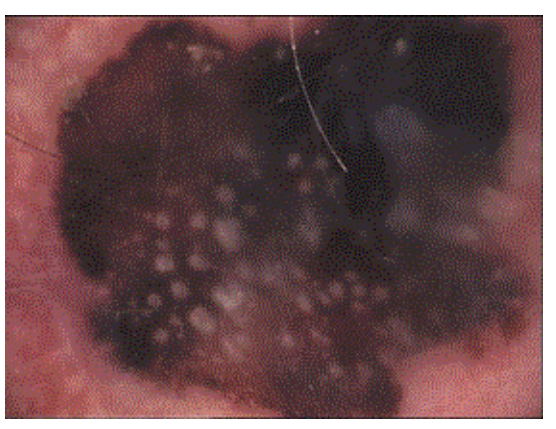

Figure 2: Dermoscopy of SSM.

The tumor reached papillary and reticular dermis, and dense lympho-plasmocytic inflammatory response was found in the infiltrative edge. Sub epidermal individual atypical melanocytes in 
lymph nodes were noted in the sample, and SNL, i.e., extirpation of the first sentinel lymph node was recommended. Conclusion: Superficial spreading melanoma Clark 4, level pT3b, Breslow 2,6 mm, with invasion of lymph nodes present.

\section{Case Study II}

A 74 year old patient asked for dermatological examination because of injury of a mole in the hairy part of his head and occasional bleeding. Anamnesis on the duration of the disease is unreliable. Photo-type 1 . Before the age of 20 he had had several sunburns. At the moment of the examination a $10 \mathrm{~mm}$ tumor nodule of grey-pink color was noticed in the right parietal region with a slightly elevated dark macula of irregular contours (Figure 3).

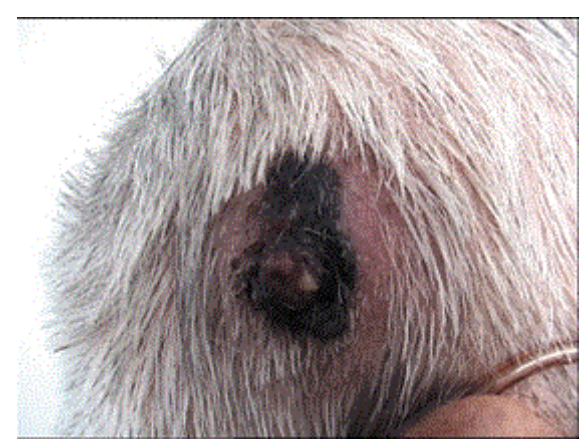

Figure 3: Nodular melanoma (NM).

The tumor nodule easily bled on palpation. Dermatoscopic examination showed the following structures: homogeneous area, irregular dots/globules and irregular vessels vs. "poppy field" sign in Figure 4 .

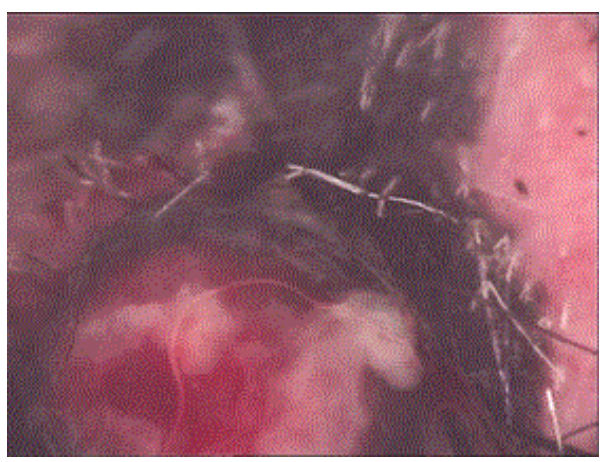

Figure 4: Dermoscopy of nodular melanoma.

Nodular melanoma from pre-existing epidermal-dermal nevus, Clark 4, level pT4b, Breslow $10 \mathrm{~mm}$.

\section{Discussion}

Numerous risk factors for appearance of melanoma have been identified up to date, but exposure to the sun UV-radiation is the most significant. Recent studies have shown that head and neck melanoma occurs more frequently in persons who were chronically exposed to sunlight during their life, whereas melanoma of lower legs and upper back and chest are linked to intermittent exposure to UV-rays, most often as a result of visiting "sunny countries" or recreational exposure [6]. Persons with red or blond hair, light eyes, a higher number of so called common nevi or one and/or more dysplastic nevi including a positive personal and/or family history of melanoma, have a higher risk for occurrence of melanoma. Studies have shown that patients with surgically treated melanoma develop another primary skin melanoma in $5-10 \%$ of cases [7].

Dermatoscopy (epilumenescence microscopy, dermoscopy) is in vivo non-invasive and painless diagnostic method used to show skin structure which cannot be seen by naked eyes: epidermis, dermoepidermal junction and papillary dermis [8]. Its basic use includes diagnostics of pigmented skin tumors, primarily melanocytic, but also non-melanocytic ones. Differentiation between these two types is the first step in dermatoscopy, whereas the second step is to recognize lesions as malign or benign based on different dermatoscopic algorithms [8]. In clinical practice experienced dermatologists performing dermatoscopy mostly apply the first-step melanocytic algorithms (pattern analysis), i.e., they use the analysis of various dermatoscopic structures and colors. In general, clinical reliability of melanoma diagnostics by "naked eye" is assessed to be around $65 \%$, whereas dermatoscopy significantly improves reliability to around 5-30\% [9].

Nowadays there is a real need to advance early detection of scalp melanoma because of its significantly worse prognosis as compared with melanoma of other anatomic locations [10]. So far there have been very few descriptions of dermatoscopic structures of melanoma on the scalp and the first case was demonstrated and published by Zalaudek et al. in 2004 [11]. That case describes scalp melanoma with multi-component global structure, i.e., atypical pigment network, irregular streaks and regression structures. Dermatoscopic structures in the case had morphologically almost identical characteristics of melanoma located on trunk, as opposed to face melanoma, which shows completely different dermatoscopic structures: asymmetric follicular openings, annular-granular pattern, rhomboidal structures, homogeneous areas and slate-grey aggregated dots [12]. In the differential diagnosis of scalp melanoma blue nevus is on the first place (common or classic blue nevus), whereas a variant of cellular blue nevus is usually found in the area of gluteus [13]. The differential diagnosis may also include tumors classified as non-melanocytic, primarily pigmented basal cell skin cancer, acanthotic type of seborrheic keratosis, and pigmented type of actinic kratosis.

There is a dermatoscopic tracing of the so called clue to direct the dermatologist performing dermatoscopy to the right diagnosis, and to the recommendation for further choice of treatment or just further dermatoscopic follow-up [14]. In the scalp region metastases of melanoma of some other anatomic locations of skin may be found, including cutaneous metastases of other cancers such as breast cancer [15], which clinically imitate malign melanoma of the scalp. Melanoma is a common tumor in human pathology. Generally, incidence and mortality vary in the world depending on risk factors primarily. Scalp melanoma is classified as hidden melanoma, and due to delayed diagnostics it is considered to be an "invisible killer". As it has a worse prognosis as compared with melanoma on other anatomic locations, the examination of the scalp should be a mandatory part of the clinical-dermatoscopic skin examination (TBSE-total body skin examination). 
Citation: Drljevic I, Drljevic K (2017) Visualization of Different Morphological Structures within Pigmented Melanocytic Skin Lesion Melanoma: Case Studies. J Pigment Disord 4: 262. doi:10.4172/2376-0427.1000262

Page 3 of 3

\section{References}

1. Pavlovic MD, Karadaglic Đ, Kandolf L (2000) Melanom kože i sluzokoža U: Karadaglic Đ. i sur. ur., Dermatologija. Beograd: Vojnoizdavacki zavod i Versal press 927-961.

2. Barnhill RL, Mihm MC Jr., Fitzpatrick TB, Sober AJ, Kenet RO, et al (1993) Neoplasms: malignant melanoma. Dermatology in general medicine. New York: MacGraw-Hill, pp: 1078-1117.

3. Herr MW, Holtel M, Hall DJ (2008) Skin cancer: Melanoma. Emedicine Otorinolaryngology and Facial Plastic Surgery. Medscape.

4. Benmeir P, Baruchin A, Lusthaus S, Weinberg A, Ad-El D, et al. (1995) Melanoma of the scalp: the invisible killer. Plast Reconstr Surg 95: 496-500.

5. Cox NH, Aitchison TC, Sirel JM, MacKie RM (1996) Comparison between lentigo maligna melanoma and other histogenetic types of malignant melanoma of the head and neck scottish melanoma group. $\mathrm{Br}$ Cancer 73: 940-944.

6. Zalaudek I, Giacomel SJ, Leinweber B (2007) Scalp melanoma. In: Color Atlas of Melanocytic Lesions of the Skin. Berlin: Springer-Verlag, pp: 265-269.

7. Markovic SN, Erickson LA, Rao RD, Weenig RH, Pockaj BA, et al. (2007) Malignant melanoma in the 21st century, part 1: epidemiology, risk factors, screening, prevention, and diagnosis. Mayo Clin Proc 82: 364-380.
8. Braun PR, Robinovitz SH, Oliviero M, Kopf WA, Saurat H-J, et al. (2007) Dermoscopic examination. In: Color Atlas of Melanocytic Lesions of the Skin. Berlin: Springer-Verlag 7-22.

9. Kittler H, Pehamberger H, Wolff K, Binder M (2002) Diagnostic accuracy of dermoscopy. Lancet Oncol 3: 159-165.

10. Shumate CR, Carlson GW, Giacco GG, Guinee VF, Byers RM (1991) The prognostic implications of location for scalp melanoma. Am J Surg 162: 315-319.

11. Zalaudek I, Leinweber B, Soyer HP, Petrillo G, Brongo S, et al. (2004) Dermoscopic features of melanoma on the scalp. J Am Acad Dermatol 51: S88-90.

12. Stolz W, Braun-Falco O, Bilek P, Burgdorf WHC, Landthaler M (2002) Colour Atlas of dermatoscopy, 2nd edn. Blackwell, London.

13. Busam KJ (1999) Metastatic melanoma to the skin simulating blue nevus. Am J Surg Pathol 23: 276-282.

14. Drljevic I, Alendar F (2010) Risk of a second cutaneous primary melanoma and basal cell carcinoma in patients with a previous primary diagnosis of melanoma: True impact of dermoscopy follow-up in the identification of high-risk persons. Serb J Dermatol Venereol 2: 144-148.

15. Marti N, Molina I, Monteagudo C, Lopez V, Garcia L, et al. (2008) Cutaneous metastasis of breast carcinoma mimicking malignant melanoma in scalp. Dermatol Online J 14: 12 